\title{
FNAC (FINE NEEDLE ASPIRATION CYTOLOGY) AS A PREOPERATIVE DIAGNOSTIC TOOL
}

\author{
S. Juthika Rai1, Gourav S. Shetty², Devan P. P3, Joseph Kalliath ${ }^{4}$ \\ ${ }^{1}$ Assistant Professor, Department of ENT, AJ Institute of Medical Sciences, Mangaluru. \\ ${ }^{2}$ Assistant Professor, Department of Cardiothoracic Surgery, AJ Institute of Medical Sciences, Mangaluru. \\ 3 Professor and HOD, Department of ENT, AJ Institute of Medical Sciences, Mangaluru. \\ 4Junior Resident, Department of ENT, AJ Institute of Medical Sciences, Mangaluru.
}

ABSTRACT

\section{BACKGROUND}

Fine needle aspiration cytology is a simple, inexpensive technique with a rapid turn-around time and is a minimally invasive technique with high specificity and sensitivity. FNAC is widely used for the diagnosis of parotid lumps, but is now also being extensively used in neck masses.

The objective of this study is to assess the sensitivity and specificity of FNAC of parotid masses with that of histopathological correlation and also to distinguish between a neoplastic and non-neoplastic lesion.

\section{MATERIALS AND METHODS}

A total of 40 patients who presented to ENT OPD at AJ Institute of Medical Sciences with swellings in the parotid region were taken retrospectively over 3 years. FNAC was done using $10 \mathrm{cc}$ syringe and 20-26G needle and stained with Papanicolaou stain (or) MayGrunwald-Giemsa stain. Histopathological specimens were stained using Haematoxylin \& Eosin (H\&E) stained with paraffin sections.

\section{RESULTS}

Out of the 40 cases studied, during this period of 3 years, there was cytohistopathological correlation in 36 cases. Pleomorphic adenoma (PA) was the most frequent lesion in this study. The sensitivity, specificity and accuracy for benign lesions was $83 \%$ and malignancy was $95 \%$.

\section{CONCLUSION}

FNAC is a simple, rapid, accurate, painless technique with excellent patient compliance and avoids unnecessary surgery or discomfort for the patient, thus making FNAC a useful tool in preoperative diagnosis of the parotid mass and plays a very important role in the management of the patient.

\section{KEYWORDS}

Parotid Swellings, FNAC, Sensitivity, Specificity, Accuracy.

HOW TO CITE THIS ARTICLE: Rai SJ, Shetty GS, Devan PP, et al. FNAC (Fine needle aspiration cytology) as a preoperative diagnostic tool. J. Evolution Med. Dent. Sci. 2017;6(27):2244-2246, DOI: 10.14260/Jemds/2017/483

\section{BACKGROUND \\ "Tumours of the parotid gland are a pathological puzzle and a source of unsatisfactory speculation".(1) Swelling involving the parotid gland may be as a result of inflammation, cyst or neoplasm. The nature of the lesion cannot be determined on clinical examination and therefore pathological examination is required for definite diagnosis in suspected cases of neoplastic disease. Nowadays fine needle aspiration cytology has emerged as an effective and sensitive technique in the diagnosis of lesions of parotid gland. Fine needle aspiration cytology is a simple, inexpensive technique with a rapid turn- around time and is a minimally invasive technique with high specificity and sensitivity. FNAC is widely used for the diagnosis of parotid lumps, but is now also being extensively used in neck masses.(2-4)}

Financial or Other, Competing Interest: None.

Submission 24-02-2017, Peer Review 20-03-2017,

Acceptance 27-03-2017, Published 03-04-2017.

Corresponding Author:

Dr. S. Juthika Rai,

Assistant Professor,

Department of ENT,

A. J. Institute of Medical Sciences,

Kuntikana, Mangaluru.

E-mail: excelcioy999@yahoo.com

DOI: $10.14260 /$ jemds $/ 2017 / 483$

\section{Aims and Objectives}

To assess the sensitivity and specificity of FNAC of parotid masses with that of histopathological correlation and also to distinguish between a neoplastic and non-neoplastic lesion.

\section{MATERIALS AND METHODS}

A retrospective study of 40 patients, who presented to the Department of Otorhinolaryngology and Head \& Neck Surgery in our institution with swellings in the parotid region over 3 years. The FNAC was performed using $10 \mathrm{cc}$ syringe and 20$26 \mathrm{G}$ needle. Aspirates were smeared on clean slides, wet smears were stained by Papanicolaou method and dry smears were stained using May-Grunwald-Giemsa (MGG) stains. The histopathological specimens were fixed in $10 \%$ formalin, routinely stained by Haematoxylin and Eosin (H\&E) stain. ${ }^{(5)}$ The specimen slides were examined and the preoperative cytology of the FNAC specimens with that of histopathological findings were compared and calculations made as to the sensitivity, specificity and accuracy for diagnosing benign and malignant lesions.

\section{Inclusion Criteria}

All parotid gland swellings with preoperative FNAC and histopathology were included in the study.

\section{Exclusion Criteria}

All head and neck swellings other than parotid swellings. 


\section{RESULTS}

Out of the 40 cases studied, during this period of 3 years, there was cytohistopathological correlation in 36 cases. Pleomorphic adenoma (PA) was found to be the most frequent lesion in this study. The sensitivity, specificity and accuracy for benign lesions was $83 \%$ and malignancy was $94 \%$. FNAC was performed on 40 patients with palpable parotid swelling. Out of the 40 cases, 22 were pleomorphic adenoma, 6 were of chronic sialadenitis, 2 were Warthin's tumours, 6 were mucoepidermoid carcinomas, 4 were acinic cell carcinomas. In which, 30 were reported as benign lesions and 10 were reported as malignant lesions.

\begin{tabular}{|c|c|}
\hline FNAC & No. of Cases \\
\hline Pleomorphic Adenoma & 22 \\
\hline Chronic Sialadenitis & 6 \\
\hline Warthin's Tumour & 2 \\
\hline Mucoepidermoid Carcinoma & 6 \\
\hline Acinic Cell Carcinoma & 4 \\
\hline
\end{tabular}

Out of these 40 cases, which underwent surgical excision followed by histologic evaluation, 16 cases were of pleomorphic adenoma, 6 cases of chronic sialadenitis, 2 cases of Warthin's tumour, 3 cases of parotitis, 4 cases of mucoepidermoid carcinoma, 4 cases of acinic cell carcinoma, 5 cases of adenoid cystic carcinoma were reported. In which, 27 were reported as benign and 13 were reported as malignant. Out of 40 cases, FNAC and histopathological correlation was available for 32 cases; remaining 8 cases had only cytological diagnosis. Pleomorphic adenoma was the most common benign lesion whereas mucoepidermoid carcinoma was the most common malignant lesion.

\begin{tabular}{|c|c|}
\hline Histopathological & No. of Cases \\
\hline Pleomorphic Adenoma & 16 \\
\hline Chronic Sialadenitis & 6 \\
\hline Warthin's Tumour & 2 \\
\hline Parotitis & 3 \\
\hline Mucoepidermoid Carcinoma & 4 \\
\hline Acinic Cell Carcinoma & 4 \\
\hline Adenoid Cystic Carcinoma & 5 \\
\hline
\end{tabular}

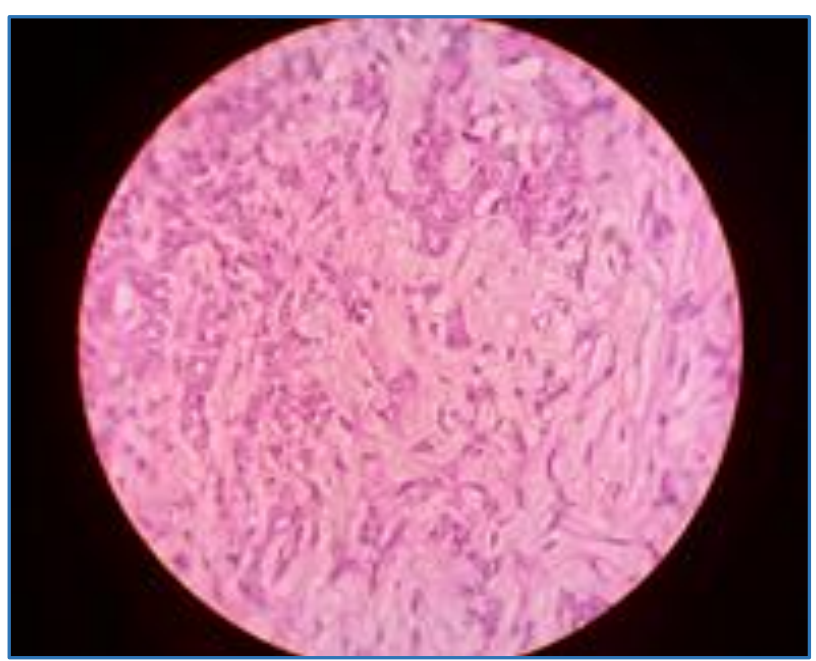

Figure 1. Microscopic View of Pleomorphic Adenoma

Microscopic features of pleomorphic adenoma: Wellencapsulated tumour tissue with heterogenous stromal elements consisting of chondromyxoid, fibrous and hyaline areas, and ducts and ductules of varying sizes lined by luminal cuboidal epithelial cells and outer layer epithelial cell. The admixed myoepithelial cells show spindle to plasmacytoid morphology.

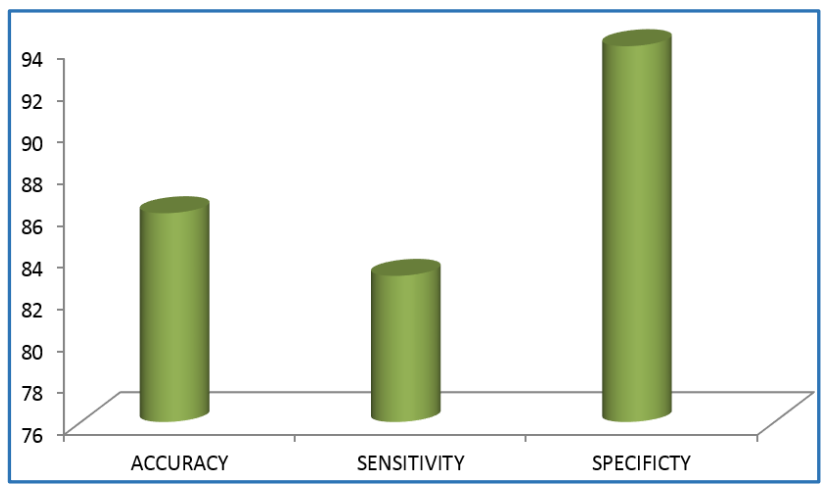

Figure 2. Comparison of Diagnostic Accuracy of FNAC

\section{DISCUSSION}

FNAC is a safe, simple, rapid and cost-effective procedure. ${ }^{6}$ Besides helping in defining the nature of lesion, in some cases FNAC also helped in making specific diagnosis. Although, management of almost all neoplastic parotid gland lesions is by surgical excision, a preoperative diagnosis if benign or malignant assists the clinician in planning the extent of surgery. Swelling of parotid glands, presents as a common problem and being readily visible creates havoc among patients. FNAC provides a convenient way to obtain a tissue based diagnosis and therefore has now become a diagnostic test of choice to solve this dilemma. Our study explains the role of this procedure in our setup to diagnose parotid gland lesions and the spectrum of disease pathology in our population. Literature review revealed a wide variation in the sensitivity and specificity of FNAC for parotid gland swelling in different populations and setups. ${ }^{6}$ Nguansangiam $S$ et al studied 133 patients of which 70 were parotid gland tumours and 63 were submandibular gland tumours to detect malignancy revealing a accuracy, sensitivity and specificity of 97\%, 81.3\% \& 99.1\% respectively. ${ }^{6}$ Zerpa et al studied 93 cases of parotid gland tumours to detect malignancy revealing a sensitivity and specificity of $57 \%$ and $95 \%$ respectively.(7) On the other hand, Pastore et al found a sensitivity and specificity of $83 \%$ and $93 \%$ respectively to detect malignancy.(8) Fakhry et al evaluated 249 parotid tumours, out of which $75 \%$ were benign and $25 \%$ were malignant.(9) The sensitivity and specificity to detect malignancy was assessed to be $80 \%$ and $89.5 \%$ respectively. The diagnostic accuracy for benign and malignant tumours was $16 \%$ and $44 \%$ respectively. We found an overall sensitivity and specificity for FNAC to detect malignancy was $83 \%$ and $94 \%$ respectively, and the diagnostic accuracy of FNAC to be $86 \%$ when compared with that of histopathology sections. There were two cases of false negative diagnosis. These two cases were one each of mucoepidermoid carcinoma and basal cell carcinoma which were initially diagnosed as pleomorphic adenoma on FNAC. The other two cases with false negative diagnosis were that of adenoid cystic carcinoma which were inaccurately diagnosed on FNAC as Warthin's tumour and pleomorphic adenoma. 


\section{CONCLUSION}

FNAC is a simple, rapid, accurate, painless technique, with excellent patient compliance and avoids unnecessary surgery or discomfort for the patient with acceptable diagnostic accuracy especially in the experienced hands. It has an important role in the preoperative evaluation and categorisation of various parotid gland lesions. Proper sampling of lesions and adequate cellularity of the smears are the prerequisites for an accurate diagnosis. The overall diagnostic accuracy of FNAC in this series was $86 \%$ with a sensitivity of $83 \%$ and a specificity of $94 \%$ for detecting malignancy. (3) Also, the confidence interval of sensitivity is from $87 \%$ to $101 \%$ and specificity is from $76 \%$ to $90 \%$. This study can be used to differentiate benign from malignant lesions of parotid gland tumours which are of utmost value in planning further appropriate management of the patient.

\section{REFERENCES}

[1] Lucas RB. Pathology of tumors of the oral tissues. $2^{\text {nd }}$ edn. Edinburg, London: Churchill Livingstone 1972:272-315.

[2] Atula T, Greenman R, Laippala P, et al. Fine needle aspiration biopsy in the diagnosis of parotid gland lesions. Evaluation of 438 biopsies. Diagn Cytopathol 1996;15(3):185-90.

[3] Filopoulos E, Angeli S, Daskalopulon D, et al. Preoperative evaluation of parotid tumors by fineneedle biopsy. Eur J Surg Oncol 1998;24(3):180-3.
[4] Choudhury AA, Sultana T, Siddique BH, et al. Diagnosis of parotid gland mass by the fine needle aspiration cytology (FNAC) and its histopathological correlation2 years study in BSMMU, Dhaka. Bangabandhu Sheikh Mujib Medical University Journal 2011;4(2):65-9.

[5] Qizilbash AH, Sianos J, Young JE, et al. Fine needle aspiration biopsy cytology of major salivary glands. Acta Cytologica 1985;29(4):503-12.

[6] Nguansangiam S, Jesdapatarakul S, Dhanarak N, et al. Accuracy of fine needle aspiration cytology of salivary gland lesions: routine diagnostic experience in Bangkok, Thailand. Asian Pacific Journal of Cancer Prevention 2012;13(4):1583-8.

[7] Zerpa ZV, Gonzales CMT, Porras AG, et al. Diagnostic accuracy of fine needle aspiration cytology in parotid tumors. Acta Otorrinolaringol Esp 2014;65(3):157-61.

[8] Pastore A, Borin M, Malagutti N, et al. Preoperative assessment of salivary gland neoplasm with fine needle aspiration cytology and echography: a retrospective analysis of 357 cases. Int J Immunopathol Pharmacol 2013;26(4):965-71.

[9] Fakhry N, Antonini F, Michel J, et al. Fine needle aspiration cytology in the management of parotid masses: evaluation of 249 patients. Eur Ann Otorhinolaryngol Head Neck Dis 2012;129(3):131-5. 